\title{
The multiaxial behavior of filled polypropylene parts by drop-weight impact test
}

\author{
Ales Mizera ${ }^{1, *}$, Martin Mizera ${ }^{1}$, Milan Navratil $^{1}$, Stepan Sanda $^{2}$, and Michal Opocensky ${ }^{3}$ \\ ${ }^{1}$ Tomas Bata University in Zlin, nam. T. G. Masaryka 5555, 76001 Zlin, Czech Republic \\ ${ }^{2}$ DOMA GmbH, R\&D Department, Gewerbegebiet 2, D - 94553 Mariaposching, Germany \\ ${ }^{3}$ TREVOS, a. s., R\&D Department, Masov 34, 51101 Turnov, Czech Republic
}

\begin{abstract}
This study deals with the multiaxial behaviour of reinforced polypropylene with $30 \%$ of glass fibre (PP30GF) and virgin polypropylene (PP). The impact behavior of these two materials is very needed to know for the possible modification of these two materials to obtain the better material properties. The injection moulded PP, and PP30GF samples were subjected to the penetration test at different set potential energies, and the results were subsequently evaluated and discussed. It was found out that PP has better behaviour at the multiaxial stress than PP30GF. It is possible to claim that for the application more demanding to the impact loading, pure PP is more suitable choice of the polymeric material.
\end{abstract}

\section{Introduction}

Polypropylene (PP) is a thermoplastic semi-crystalline polymer belonging to the polyolefin family owning good mechanical and dielectric properties. This polymer is considered as a commodity polymer, and it is very often used in the area of the automotive, chemical and the electrical industry for the production of electrical insulation thanks to its low dielectric loss and very good heat resistance [1-4]. In comparison to the other polyolefin, e.g. polyethylene, PP has the higher mechanical resistance and rigidity because of its higher crystallinity and point of melting [5]. Despite good mechanical properties of $\mathrm{PP}$, it is possible to obtain better mechanical properties using fiberglass reinforcement as a modification. Organofunctional silane compounds together with the graft or block polyolefin copolymers are used to promote the adhesion of reinforced plastics with fiber. This compound together with PP was twin-screw extruded, immediately quenched in water and cooled in air to the ambient temperature. The samples for testing were injection moulded, and subsequently, mechanical and thermal properties were measured. The results showed that samples from blend above-mentioned showed an increase in tensile modulus, bending modulus, tensile strength, bending strength and notched impact strength compared to pure PP. The data also showed that thermal stability of modified PP was better in comparison to the pure one [6].

The effort to obtain light-weight high-strength reinforcement PP led the scientists to create the blend from PP, hollow glass microspheres and short bamboo fibre. After preparation of the blend and samples, the measurement of mechanical properties was done. The use of short bamboo fiber improved mechanical properties, while the use of hollow glass microspheres controlled the increase in the density of the short bamboo fibre addition [7].

The reinforcement of PP with talc or short glass fibre had in one study the same influence on the creep deformation, respectively did not change the creep mechanism significantly. The creep strength was improved in comparison to the pure PP [8]. Next possible filler for reinforcement to obtain better mechanical properties of PP are multi-walled carbon nanotubes. Hui Zhang and Zhong Zhang created multiwalled carbon nanotubes/polypropylene composites which compounded using a twin-screw extruder. The nanotubes had different lengths of 1-2 $\mu \mathrm{m}$ and 5-15 $\mu \mathrm{m}$ and similar diameter of $10-30 \mathrm{~nm}$. The nanotubes were applied at a constant volume content of $1 \%$. After testing, they found out that both longer and shorter nanotubes can improve the impact energy of PP matrix at temperatures above glass transition temperature. The greater effect for improvement of the impact energy the longer nanotubes had in comparison to shorter ones [9].

The combination of PP, polyamide 66, molybdenum disulphide, silicon carbide and alumina was investigated. The scientists found that the addition of micro fillers had the hybrid effect on mechanical properties of this blend. The tensile strength and strain were decreased due to the hybrid effect of fillers above-mentioned. The flexural strength at first decreased but increased after the addition of micro fillers. The improvement of hardness and the density was found out. The improvement of the fracture toughness around $188 \%$ was noticed after using these micro fillers [10].

Many research papers concentrating on the impact behaviour of PP have been written, but not so many 
scientists used for these articles the drop-weight impact test. This study is focused on the impact behaviour of pure and glass fibre reinforced PP. The multiaxial behaviour of both polypropylenes was tested on dropweight impact test machine at different set potential energies. The results were subsequently discussed and evaluated. It was found out that pure PP is more suitable material for more demanding application to the impact loading.

\section{Experimental}

Virgin and reinforced Polypropylene with $30 \%$ of glass fibre were used as the basic polymer materials (TATREN, IM 25-75 and Scolefin 53 G 10) [11]. An ARBURG Allrounder $470 \mathrm{H}$ Advance Injection moulding machine was used for sample preparation, with the processing conditional on complying with polypropylene (PP and PP30GF) producer's recommendations, as can be seen in Tab. 1. The samples were in the shape of plates with dimensions $100 \times 100 \times 3$ $\mathrm{mm}$ according to ISO 6603-2.

Injection moulded PP, and PP30GF samples were tested on drop-weight impact test machine Zwick HIT230F according to ISO 6603-2 at the ambient temperature of $23^{\circ} \mathrm{C}$. The scheme of this arrangement is possible to see in Figure 1. As the main parameter was used potential energy, which was set on the testing machine. 15 samples at each set potential energy $(30,50$, $100,150,200$ and $230 \mathrm{~J}$ ) were tested and then maximum impact force was statistically evaluated in program TestExpert II, MS Excel 2016 and MiniTab 16. At the end of the test, crack surface was evaluated at each potential energy.

Table 1: PP and PP30GF set injection moulding parameters.

\begin{tabular}{|l|c|c|}
\hline \multirow{2}{*}{ Injection Parameters } & \multicolumn{2}{|c|}{ Values } \\
\cline { 2 - 3 } & PP & PP 30 \% GF \\
\hline Injection Pressure $[\mathrm{MPa}]$ & 70 & 80 \\
\hline Injection velocity $\left[\mathrm{mm} \cdot \mathrm{s}^{-1}\right]$ & 40 & 50 \\
\hline Holding Pressure $[\mathrm{MPa}]$ & 55 & 60 \\
\hline Cooling Time $[\mathrm{s}]$ & 25 & 20 \\
\hline Mould Temperature $\left[{ }^{\circ} \mathrm{C}\right]$ & 30 & 40 \\
\hline Melt Temperature $\left[{ }^{\circ} \mathrm{C}\right]$ & 215 & 235 \\
\hline
\end{tabular}

\section{Results and discussion}

This study is concentrated on the multiaxial behaviour of virgin and reinforced polypropylene with $30 \%$ of glass fibre by drop-weight impact test. Injection moulded PP and PP30GF parts were tested on penetration where set potential energy in the range from 30 to $230 \mathrm{~J}$ and the results were subsequently evaluated.
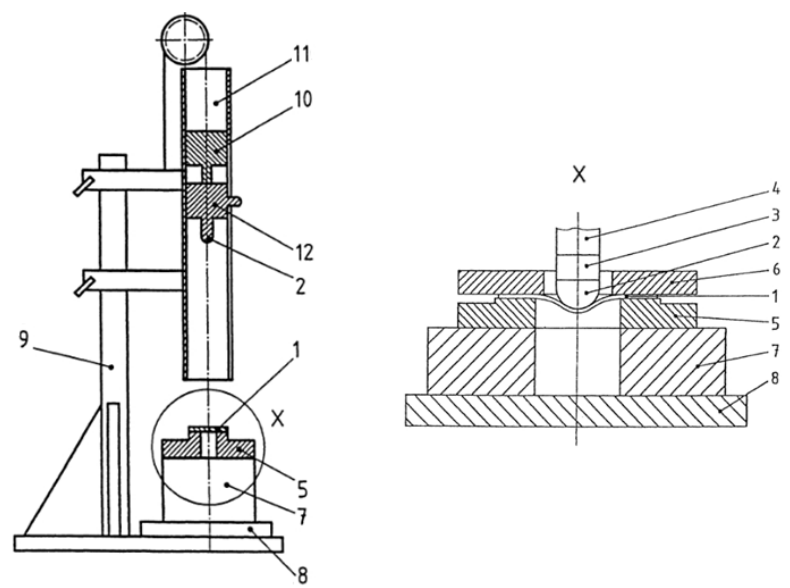

Fig. 1. Drop-weight impact test scheme.

1 - Test specimen; 2 - Hemispherical striker tip $10 \mathrm{~mm} ; 3$ Force sensor; 4 - Shaft; 5 - Test specimen support; 6 Clamping ring (optional); 7 - Base; 8 - Acoustic isolation (optional); 9 - Stand for falling-dart system; 10 - Holding and release system for weighted striker; 11 - Guide shaft for weighted striker; 12 - Weighted striker $23,77 \mathrm{~kg}$.

\subsection{Maximum impact force}

PP30GF statistical evaluation of the measurements is shown in Table 2. This article is continuing of the last study about PP optimization of fall height [8]. Therefore, changes in virgin and reinforced polypropylene can be evaluated by penetration test (multiaxial loading).

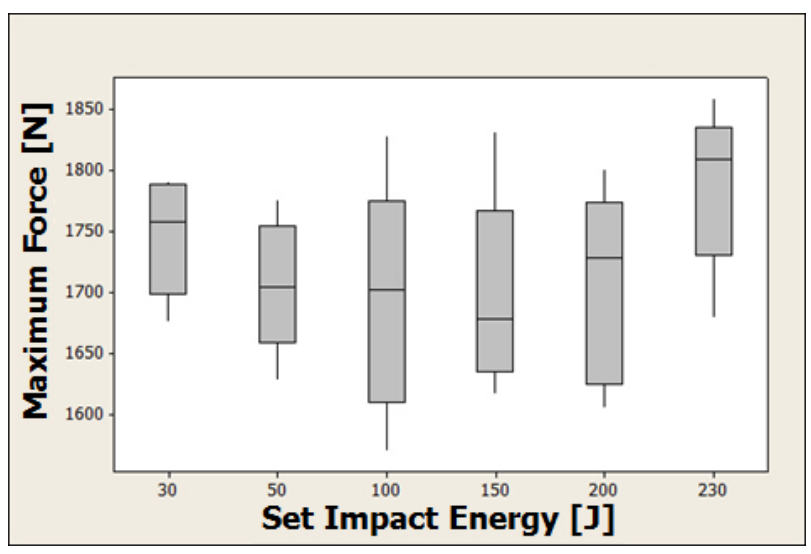

Fig. 2. PP30GF Boxplot graph of maximum force at set potential energy.

In Figure 2 the PP30GF maximum force at set potential energy is displayed. Measurements are burdened with a high error because of a non-defined arrangement of glass fibres. Therefore, the median was chosen to compare the maximum force values. PP30GF value median at $30 \mathrm{~J} 1758 \mathrm{~N}$ was evaluated, with increasing set potential energy value of maximum impact force is slightly decreasing up to $150 \mathrm{~J}$. Another increase in set potential energy has led to a rapid rise in maximum force on value $1808 \mathrm{~N}$ at $230 \mathrm{~J}$. However, the differences of the measured values are within the error measurement range.

The PP and PP30GF maximum impact force change in $\%$ can be seen in Figure 3. The changes move in $17 \%$ from the PP sample with no penetration to last 
Table 2. PP $30 \%$ GF maximum force statistical evaluation at the set potential energy.

\begin{tabular}{|c|c|c|c|c|c|c|}
\hline Set energy of fall $[\mathrm{J}]$ & \multirow{2}{*}{30} & \multirow{2}{*}{50} & \multirow{2}{*}{100} & \multirow{2}{*}{150} & \multirow{2}{*}{200} & \multirow{2}{*}{230} \\
\hline Statistical characteristics [N] & & & & & & \\
\hline Number of measurements & 15 & 15 & 15 & 15 & 15 & 15 \\
\hline Arithmetic mean & 1744 & 1704 & 1698 & 1701 & 1705 & 1789 \\
\hline Type error A & 14 & 16 & 29 & 24 & 24 & 19 \\
\hline Standard deviation & 44 & 50 & 93 & 75 & 75 & 60 \\
\hline Minimum value & 1676 & 1629 & 1571 & 1617 & 1606 & 1679 \\
\hline Median & 1758 & 1704 & 1702 & 1678 & 1728 & 1808 \\
\hline Maximum value & 1790 & 1776 & 1828 & 1831 & 1800 & 1858 \\
\hline Variation range & 115 & 147 & 257 & 214 & 194 & 179 \\
\hline
\end{tabular}

penetrated PP sample. The change of maximum impact force for PP30GF is negligible as described above. It is possible to see double times higher value of maximum impact force for PP in comparison with PP30GF. This is caused by non-defined arrangement of glass fibre, resulting from processing technology - injection moulding.

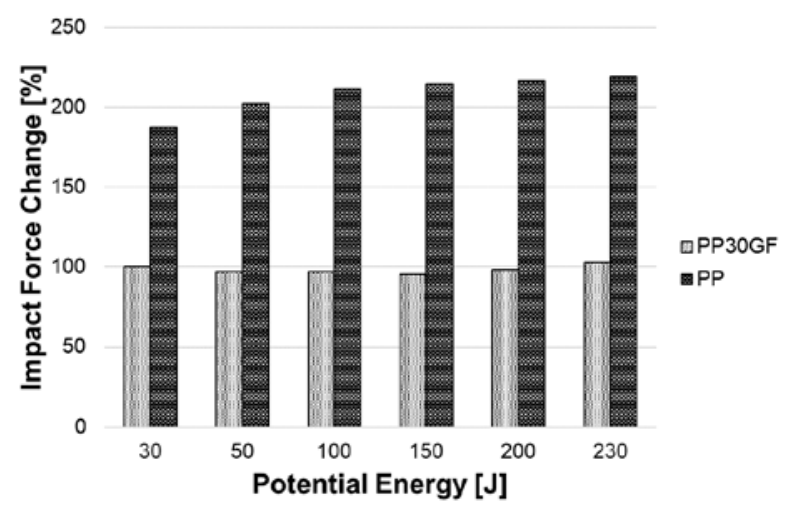

Fig. 3. PP30GF, and PP percentage change in maximum force to the prescribed base potential energy of $30 \mathrm{~J}$.

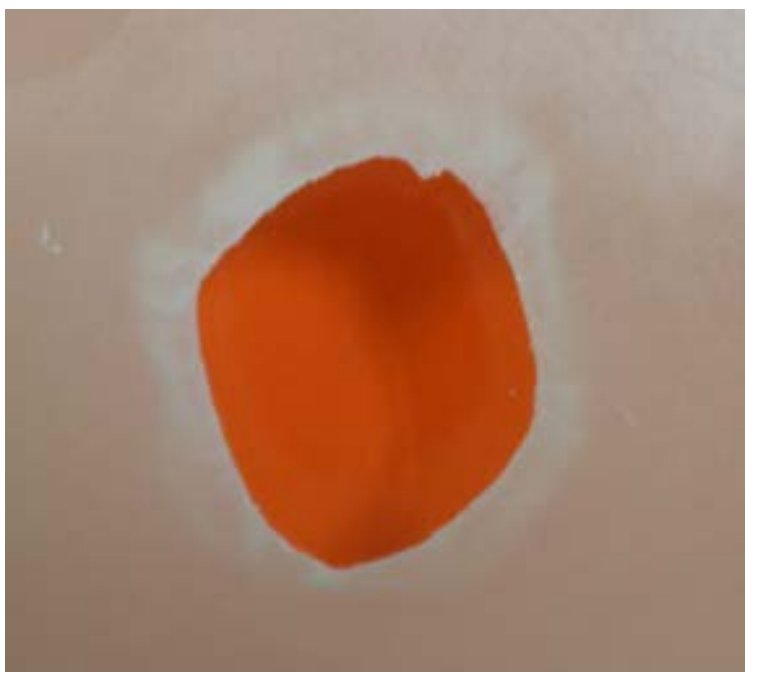

Fig. 4. PP30GF deformation after drop-weight impact test at $30 \mathrm{~J}$.

\subsection{Deformation after the test}

After the drop-weight impact test the tested parts were photographed for better idea about the deformation, and crack growth.

In Figure can be seen deformation of PP30GF at $30 \mathrm{~J}$. Through the penetration of the penetrator, sharp edges of the hole are formed. On the other hand, in Figure 5 it is shown that the PP at $30 \mathrm{~J}$ was not penetrated because of too small set potential energy which is needed for penetration. There is seen just plastic deformation of the PP material.

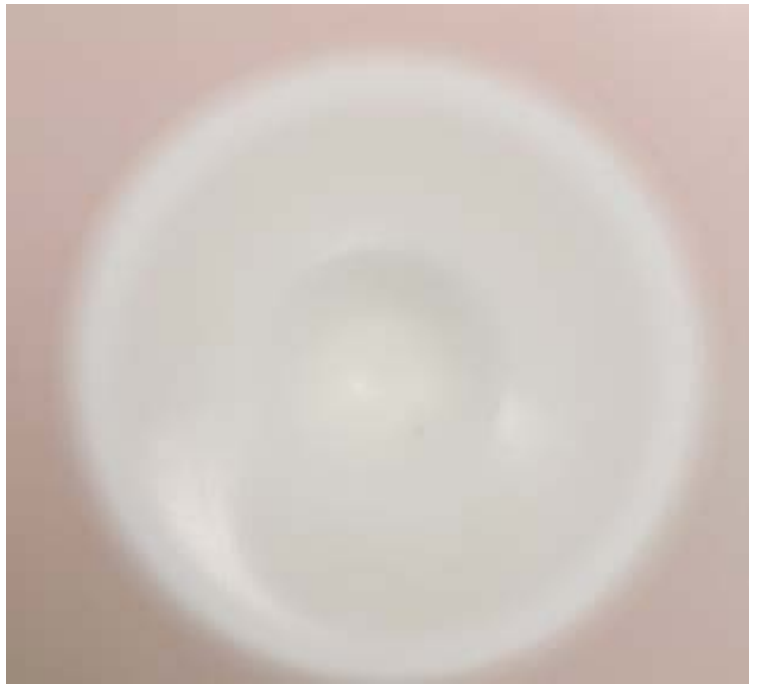

Fig. 5. PP deformation after drop-weight impact test at $30 \mathrm{~J}$.

The set potential energy of $50 \mathrm{~J}$ causes both PP30GF and PP to penetrate. In Figure 6, for PP30GF, a larger hole can be seen than the diameter of the penetrator, the material is splintered from the center to the edges. In Figure 7, in the case of PP, the material encircles the penetrator, large plastic strains can be observed. A similar trend is observed at set potential energy $230 \mathrm{~J}$ for both materials PP30GF (Figure 8), and PP (Figure 9) in comparison with deformation at $100 \mathrm{~J}$. 


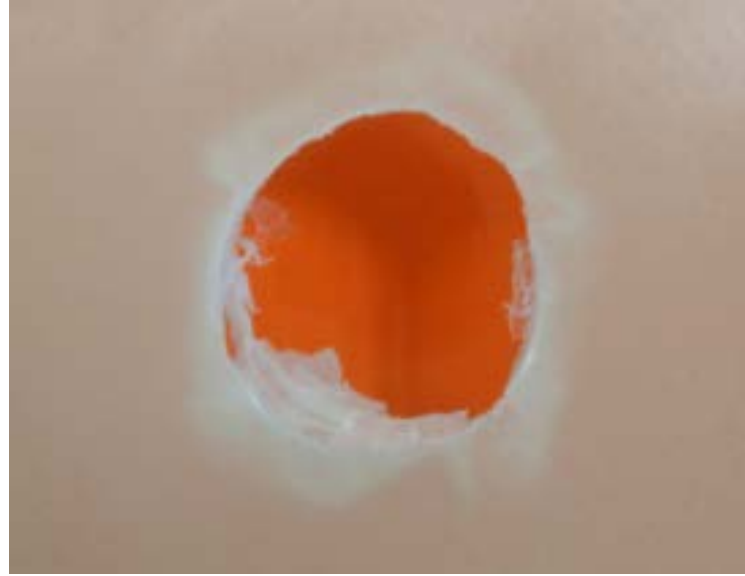

Fig. 6. PP30GF deformation after drop-weight impact test at $100 \mathrm{~J}$.

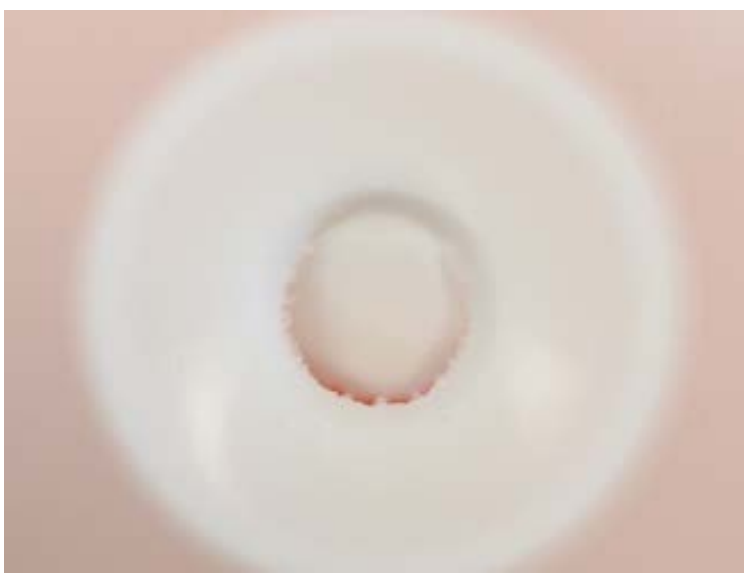

Fig. 7. PP deformation after drop-weight impact test at $100 \mathrm{~J}$.

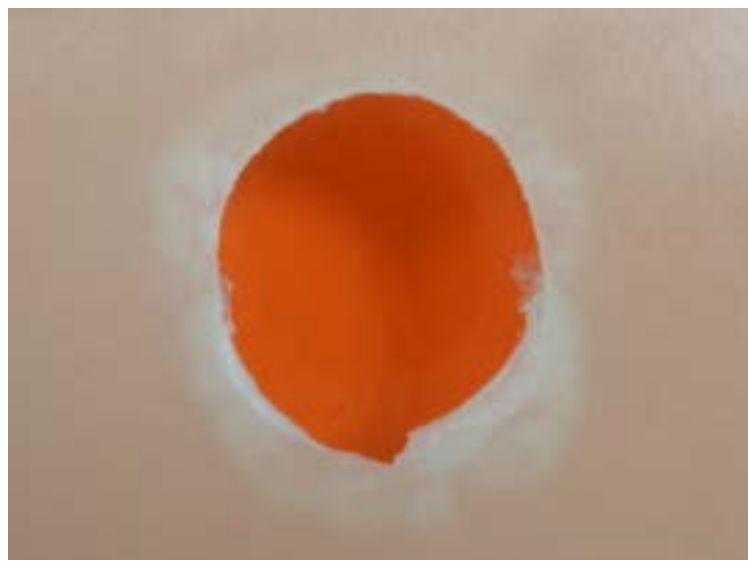

Fig. 8. PP30GF deformation after drop-weight impact test at $230 \mathrm{~J}$.

\section{Summary}

In this study the injection moulded PP30GF, and PP parts were subjected to the drop-weight impact test at a different set of potential energies. The range of potential energies was from 30 to $230 \mathrm{~J}$. Set potential energy does not affect the maximum impact force of both materials (PP30GF, and PP), but changes the character of the deformation. Maximum impact force, in case of PP, is twice as large as PP30GF value. This difference can be caused by the higher fragility of PP30GF caused by added glass fibres. It can be stated that for the application where the impact loading is often used, pure $\mathrm{PP}$ is more suitable material. In this way it is possible to test much higher amount of polymeric materials for the better knowledge of the material behavior issue.

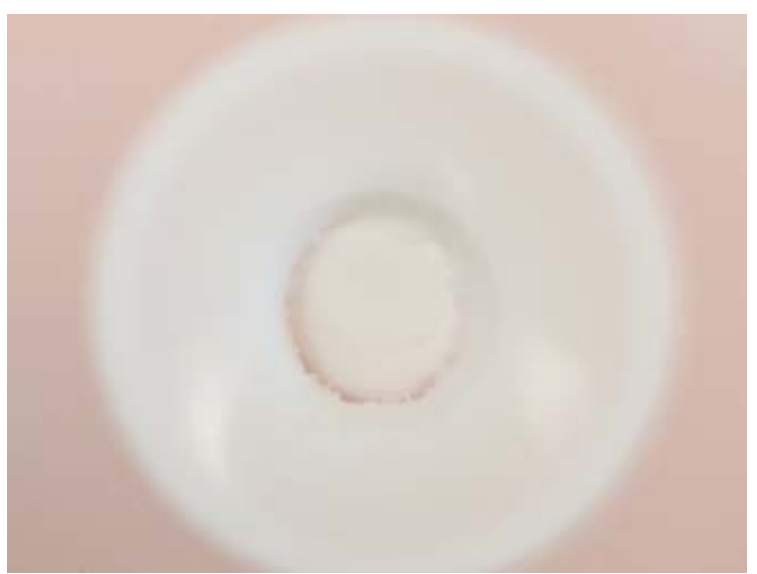

Fig. 9. PP deformation after-drop weight impact test at $230 \mathrm{~J}$.

This paper is supported by the internal grant of TBU in Zlin No. IGA/FT/2018/012 funded from the resources of specific university research, by the Czech Ministry of Industry and Trade in Program "Aplikace" No. CZ 01.1.02/0.0/0.0/16 084/0009949 and by the Ministry of Education, Youth and Sports of the Czech Republic within the National Sustainability Programme project No. LO1303 (MSMT-7778/2014) and also by the European Regional Development Fund under the project CEBIA-Tech No. CZ.1.05/2.1.00/03.0089.

\section{References}

1. E. Suljovrujic, S. Trifunovic, D. Millicevic, Polym. Degrad. Stabil. 95 (2010)

2. V.Senkerik, M.Stanek, M. Ovsik, L. Hylova, Key Engineering Materials 756 11-18 (2017)

3. M. Reznicek, M. Bednarik, L. Hylova, D. Manas, MATEC Web of Conferences 76 1-4 (2016)

4. V. Senkerik, M. Stanek, M. Ovsik, Materials Science Forum 919 136-143 (2018)

5. D.H. Han, S.H. Shin, S. Petrov, Radiat. Phys. Chem. 69 (2004)

6. L.H. Zhu, J.F. Sheng, Z.F. Guo, X.S. Ju, S. Li, Y.F. Chen, J. Luo, Polym. Polym. Compos. 22 381-385 (2014)

7. N. Kumar, S. Mireja, V. Khandelwal, B. Arun, G. Manik, Compos. Part B-Eng. 109 277-285 (2017)

8. M. Eftekhari, A. Fatemi, Compos. Part B-Eng. 97 68-83 (2016)

9. H. Zhang, Z. Zhang, Eur. Polym. J. 43 3197-3207 (2007)

10. B.V. Lingesh, B.N. Ravikumar, B.M. Rudresh, Trans. Indian Inst. Met 70 1743-1753 (2017)

11. L. Hylova, A. Mizera, M. Manas, D. Manas, S. Sehnalek, M. Kubisova, WSEAS Transactions on Environment and Development 14 243-250 (2018) 